\title{
“THE OLDER I GET THE LESS I TRUST PEOPLE" CONSTRUCTING AGE IDENTITIES IN THE WORKPLACE
}

\author{
Jo Angouri
}

\begin{abstract}
In 2006 laws banning age discrimination came into effect in the UK. Even though unions seem to suggest that 'age' is a very common form of discrimination, it does not typically attract (at least as yet) the same attention as other more widely discussed cases. Age discrimination is typically associated with discourses around an 'ageing workforce', however it affects both younger and older employees.

Looking closer at 'ageing' discourses it becomes apparent that the boundaries between 'old' and 'young' are not as clear cut as a first reading would suggest. Further to this, recent sociolinguistic research has repeatedly shown that (age or other) identity is not something people 'have' or 'are' but something people 'do' (e.g., Holmes 2006; Coupland 2009). Accordingly, the aim of this paper is to discuss and problematise the ways in which employees construct age identities in the complex system of white-collar workplaces.

The paper draws on recordings of real life routine meeting data featuring primarily employees in a small/medium enterprise (SMEs). Special attention is paid here to one member of the team, Cynthia the youngest member of staff. The discussion also draws on interview data in order to further analyse perceptions and representations of 'age differences' in this context. The analysis shows the complex process of negotiation of identity where chronological age is related to 'expertise' and 'experience' and becomes an important resource participants draw upon in the process of self -and other- positioning.
\end{abstract}

Keywords: Age identities; Young employees; Professional age; Small medium enterprises (SMEs).

\section{Introduction ${ }^{1}$}

Discourses of age discrimination have begun to gain increased attention in the public domain. Even though age discrimination affects all age groups (Duncan and Loretto 2004), the debate is often associated with 'older' age groups. Given the 'ageing' population and low birth rates, common features in a number of countries, exclusion of 'older' age groups from the job market has serious implications which could explain the emphasis placed on chronologically older employees. However an interesting paradox

${ }^{1}$ I would like to express my appreciation to Orion's staff who allowed their workplace interactions to be recorded. Special thanks to Cynthia for being so generous with her time and for the long discussions. 
can be noted; governments urge the employees to continue working and the companies to provide opportunities and adapt to the, at least alleged, exigencies of $21^{\text {st }}$ century economies. At the same time however workplaces seem to be less keen to either recruit or be proactive in keeping their 'older workers' on payroll (Patrickson and Ranzijn 2004). Indicative of the significance placed on early exit, an issue directly associated with 'older' employees, is the suggested costs to the economy; namely about $£ 16$ billion a year on lost GDP and $£ 3$ to 5 billion per annum on extra benefits and taxes (Performance and Innovation Unit, 2000: 5).

Foregrounding 'older' employees however is problematic in more than one way. As sociolinguistic research has indicated (e.g., Holmes 2006) categories like 'old' and 'young' and the boundaries between them are anything but clear cut. At the same time, focusing on abstract perceptions of 'older' workers, excludes age groups that have been affected at least as much by age discrimination. Despite the scarcity of research, studies already report that employees below the age of 30 report high levels of age discrimination (Snape and Redman 2003). And finally, singling out isolated age groups, fails to see the change in the workplace holistically and critically. As Roberts (2006) argues any worker old or young is part of a complex system and issues of entering, exiting or remaining active go "beyond the individual workplace to arguments about what kind of society we want to live in and the role that institutions, including work organizations, have to play in such a society” (2006: 82). Seeing this through the lenses of post capitalist economies the discourses of age acquire a different significance and go beyond specific age groups. To take this further, conceptualising age and ageing as a linear process and relating the debate to skills and the experience of different age groups, implies on one hand that age can be measured by a certain predefined currency (usually years) and that employees join a workplace and acquire or develop skills throughout their work life (in an accumulative way) whereby they turn from novice (often used to signify young) to old timers (which can signify 'older' employees). This approach however reduces 'age' to a person's chronological age and does not take into account either the complexity of the phenomenon or of modern workplaces or the dynamic nature of 'learning' at work which is 'collective' rather than bi-directional (between a 'teacher' and 'student') (see Engeström 1987 on extensive learning and Mørck 2011).

Against this backdrop, the aim of this paper is to discuss perceptions of age in one small/medium firm and to focus on the case of the youngest employee Cynthia. The aim here is not to make a generalisable case but to discuss 'age' through Cynthia's perspective and to link micro discourses with the wider context.

SMEs and family businesses have been characterised as the 'backbone' or European economies. According to The Department for Business Innovation and Skills, SMES "accounted for 99.9 per cent of all enterprises" and "together accounted for more than half of employment (59.8 per cent) and turnover (49.0 per cent) in the UK”. (BIS, 2010: 1). Despite these figures SMEs are still relatively under researched (compared to large and multinational companies). A recent report (Neathey 2006) on the impact of the 2006 UK law banning age discrimination suggested that small firms are least likely to have made changes in anticipation of the law (17\% of SMEs compared to $65 \%$ for larger employers). At the same time small firms operate on the basis of personal networks more than their larger counterparts. This makes them potentially more open to 
diversity (e.g., Cassell et al. 2002) but also more reluctant to adopt HR related practices (including equality and diversity policies) (e.g., Woodhams and Lupton 2005).

As relevant business literature has shown (e.g., Holliday 1995; Spence 1999; Granovetter 2000) small firms differ from large companies not only in size but also in the way business is done. The most relevant for the discussion here is the well discussed importance of personal relationships. Given the small workforce (often $<10$ employees as is the case of the company discussed here) personal relationships between employees who may be either family members or work together over long periods of time are central and influence daily practice. In this context the roles of senior manager, company director, family member and close friend are intertwined. This of course is not to suggest that relationships are not always relevant to any workplace. In fact research (e.g., Holmes and Stubbe 2003; Locher 2004) has clearly shown that employees work hard not to damage their rapport in their work context. However, in a firm where a small group of employees constitute the whole workforce, individual relationships acquire an increased weight as there are no anonymous structures, no rapid changes in team structures, less mobility, no headquarters, no invisible top management and so on. As nicely put by Spence "small firms are an interesting example of organisations that are commonly reliant on networks of dynamic personal relationships" (2004: 2). Even though this would provide support to the claim that SMEs would be more sensitive to equality and diversity issues, Woodhams and Lupton's (2005) recent work has shown a more complex picture. Even though their focus was on equal opportunities, their work suggests that small firms vary greatly and despite those who enthusiastically engage with the equality agenda, there is also evidence of "widespread failure to adopt basic procedures and, in some cases, comply with minimum legislative requirements" (Woodhams and Lupton 2005: 165). Overall what is common in most studies in the SMEs context is an emergent 'mixed picture' given the diverse profile of the companies even within the same sector (e.g., Holliday 1995; Jones 2003) as well as an emphasis on the need for further research.

Accordingly, this paper aims to address this gap and to discuss 'age' identity in this particular context. The paper focuses on the perceptions of one employee Cynthia. The paper is organised as follows; the first section explores the concept of identity and attempts to position this work in relation to theories and studies in this area of scholarship. The discussion moves then to the concept of 'age' focusing on past (socio) linguistic research. The next sections are concerned with the method and the analysis of excerpts from business meetings and interview data. The paper closes by highlighting the complexity of age identities and the implications of the study for further research in the SME context.

\section{Negotiating and constructing 'self' in interaction}

This paper focuses on identity construction in the context of a small but rapidly growing firm and discusses how self identity is claimed and negotiated with other employees in this context. Understanding 'self' as a social construct is certainly not new to social sciences. The influential symbolic interactionist tradition (Gecas 1982 for an overview) has concerned itself with the dialogic relationship between self and society. And Cooley 
as early as 1902 suggested that social self is a 'looking glass-self', where people develop their sense of self through identities projected on them by their social environment. Mead in his seminal work (1934: 140) also argued that:

The self, as that which can be an object to itself, is essentially a social structure, and it arises in social experience. After a self has arisen, it in a certain sense provides for itself its social experiences, and so we can conceive of an absolutely solitary self. But it is impossible to conceive of a self arising outside of social experience.

(Role) Identity theory (e.g., Stryker 1980) and Social Identity theory (e.g., Tajfel and Turner 1979) have discussed how the roles an individual occupy (identity theory) and membership to (a number of different and overlapping) social groups (social identity theory) is inextricably linked to self identification processes (Stets and Burke 2000 for a comparison between the two).

Although there is consensus in that what an individual does (e.g., what roles one takes up) is inextricably linked to identity, for identity theory "the core of an identity is the categorization of the self as an occupant of a role, and the incorporation, into the self of the meaning and expectations associated with that role and its performance (Burke and Tully 1977; Thoits 1986)" (Stets and Burke 2000: 225). In contrast, social identity theory places emphasis on group membership. According to the latter, through belonging to (a) group/s the individual ascribes identity to self in line with the (broadly defined) characteristics of the in group. The group provides a sense of self and the group norms affect the behaviour of the individual (Hogg, Hardie and Reynolds 1995). Both theories also refer to 'personal' identity but without placing too much emphasis on the individual 'self' (Terry et al. 1999). As discussed by Hitlin (2003: 132) “[p]eople's selfconceptions do not consist solely of their various role and group membership”. Hitlin's research (2003) attempts to bring together 'self' and 'identity' theories and makes a case for a more integrated and multilayered approach that repositions and revisits the inextricable link between the individual/self and social/other.

This is in line with recent work (Scwartz, Luyckx and Vignoles 2011) which makes a convincing case for an integrated view on identity and which problematises the use of terminology (identity/role/self) across social sciences where the term is used to index different theoretical traditions and research paradigms. Discussing the extensive work and theories that have emerged in sociology and psychology on identity and self is not the aim of this paper and goes beyond its sociolinguistic focus, the discussion however attempts to make a case for a holistic understanding of this complex phenomenon. While Social Identity Theory has been influential in sociolinguistic research (see e.g., Accommodation Theory, Giles et al. 1991; LePage and TabouretKeller 1985), the enactment of roles in talk is not always equally theorised (Sarangi 2010 and Bamberg et al. 2011).

The stance taken here is that identities are dynamic in nature and enacted in talk. This discourse based approach sees identity as a process in a dialectal relationship with the roles individuals occupy and the groups to which they belong or aspire. Both group membership and role enactment however are not static and negotiated in interaction. Following social constructionism, the paper sees identity as not something people are or have (from an essentialist approach) but something people actively do. This does not contradict the relative stability, power and ideology related to the web of social norms 
within which individuals construct their identities (Cameron 2009). As an illustration, 'youngness' is associated with normative perceptions of linguistic and other behaviours (see Harwood et al. 1995 on age) that create expectations of performance across groups in different societies. Similarly, professional roles are expected (by the group) to be enacted and indirectly coded and indexed by certain linguistic features and other characteristics (e.g., dress code) in professional contexts. The enactment of identities and roles however is a dynamic process whereby the individual positions and brings the status quo under scrutiny (hence sometimes redefines dominant norms).

Bringing together the micro- (local) and the macro- contexts has been subject of debate between different theoretical approaches and methodological traditions in (the broadly defined) discursive approaches to identity. Bamberg et al. (2011) in their recent work provide an overview on how bottom up and top down analyses (corresponding to small and capital -d- discourses -see Gee 1999-) address what they call 'dilemmatic positions' (Bamberg et al. 2011: 178). The three 'dilemmas' discussed in this work are concerned with agency and control, difference and sameness between me and others and constancy and change. This work nicely shows how a close analysis of language can shed light and contribute to theories of identity by focusing on how social categories and a sense of self do not pre-exist the individual agency and the 'here and now' of the interaction and hence cannot be captured without an analysis of the context in which they are enacted. The discussion here is mainly focused on the first 'dilemma' referring to "whether it is the person, the I-as-subject, who constructs the way the world is or whether the me-as-undergoer is constructed by the way the world is - and how this dilemma is navigated on a case-to-case basis” (Bamberg et al. 2011: 178). This is further discussed in relation to 'age' in the next section.

\section{3. 'Age' as a personal and social identity}

Self and others' perceptions of a person's age play a significant role in identity construction processes. 'Age' as a social variable attracted attention in sociolinguistic research (particularly in relation to variation see e.g., Trudgill 1988; Labov 1994) but there is much less research on the discursive construction of age identities (Coupland et al. 1991a,b). Even though chronological age seems to be dominant in relevant discourses and is defined on the basis of calendar years, age is a multilayered concept and may indicate a stage in a person's biological or social development as well as career progression.

Sociolinguistic research on age has focused more on understanding language use of particular age groups (e.g., teenagers vs. middle age groups) and process of language change (e.g., conservatism associated with adulthood Trudgill 1974; Labov 1972). Despite this body of work, age and the interrelationship between age and other facets of identity, widely included in sociolinguistic studies (e.g., gender, social class), is still relatively under- researched. As clearly shown in seminal work in this area of scholarship (e.g., Coupland et al. 1991) there is a need for research which approaches age as dynamic concept, sees age groups as not homogeneous and which acknowledges that perceptions of age (and the roles associated with different age groups) vary depending on the wider socio-cultural context (Eckert 1997). Coupland (2004) provides 
with a very good overview of sociolinguistic studies that have focused on apparent time designs (see also Chambers 1995) and language change and highlights the need for research that also goes beyond the mainstream variationist paradigm and addresses the socio-political aspects of ageing as a dynamic phenomenon.

This paper sees chronological age as a resource individuals draw upon in constructing self/other identities in general and in the workplace in particular. In line with the work discussed earlier aging is not seen as a linear individual process but as something that is enacted in interaction and in relation to other facets of employees' identities. Special attention is paid to the relationship between chronological and professional age, which refers to expertise and also years of experience in a particular workplace.

\section{Method and data}

The paper reports on the preliminary results of a project on small and family size firms in Europe. The excerpts discussed here are drawn from a corpus of about 60 hours of recorded data which was collected in the headquarters of a small-medium sized company, Orion ${ }^{2}$, a chain of 13 franchise stores. The real-life data were collected with the consent of the participants over an initial, continuous, three month period and the second phase of this project is ongoing at the time of writing. The project takes a participatory approach and sees the research as carried out not 'on' or 'for' but 'with' the participants who are in control of the data collection (Holmes and Stubbe 2003) process and also contribute to the research design (see Cameron et al. 1992; Roberts and Sarangi 2003). The project and its design is not presented to the firm as a fait accompli but is co-shaped in relation to what the businesses are interested in exploring further regarding their own realities (Angouri 2010).

Orion participants were involved in ethnographic interviews at different stages of the project (pre and post the linguistic analyses) ${ }^{3}$. Shadowing and observations took place at the beginning of the project for one working week. Orion employs 7 people in total, each with distinct responsibilities. Table 1 presents a brief profile of the individuals involved in the meetings discussed here.

\footnotetext{
${ }^{2}$ All names are pseudonyms

${ }^{3}$ The interview and observation data will be discussed in further detail elsewhere (see also Angouri and Angelidou, fc).
} 


\begin{tabular}{|l|l|}
\hline Robert & Senior manager and company director \\
\hline Sara & $\begin{array}{l}\text { General manager and Robert's associate. Sara is } \\
\text { the line manager for the rest of the staff }\end{array}$ \\
\hline Richard & Senior Manager (production) \\
\hline Brandon & Regional franchise manager \\
\hline Cynthia & Communication manager (newcomer) \\
\hline
\end{tabular}

Table 1. Orion's staff

The meeting data presented here are drawn from two meetings and were brought up by Cynthia as examples where 'age' was salient ${ }^{4}$. Although more often than not meetings have more than one function and the researchers' classifications can be different to the participants' understanding of 'what is going on' (Holmes and Stubbe 2003) the participants perceived these meetings as having a primarily problem solving function. I take an Interactional Sociolinguistics informed approach and the focus of the discussion here is the linguistic analysis. The interviews I discuss take a discourse based approach (Odell, et al. 1983) and the participants (Cynthia in particular who is the focus of this paper) were asked to talk through the naturally occurring data. In this dataset the participants construct an account of 'what is going on' in the recording (Gumperz 1982 on playback interviews). This is, evidently, not a 'factual' account/report but a performance and co-construction of the event for and with the researcher (Block 2000). As such the interview data are seen as a distinct dataset which provides a snapshot of the participants' interpretations of the event, positioning of 'self' and 'others' (Davies and Harré 1990) and intuitions about norms and practices. This is useful for a more holistic understanding of powerful ideologies which create a web of power relations relevant to how things are done at work (and this includes the interviewee and their colleagues, in the case of workplace research, but also the interviewee and interviewer). Interview data are particularly relevant to the analyses of identity construction as they provide a different snapshot of the participants' habitus and the subtlety of the ideologies that shape and are shaped by everyday practice. Even though workplace sociolinguistic research is mainly focused on real life interaction (the concept of intuitions vs. language use is well known and documented), interview data also constitute a context where the participants negotiate their identities and status quo for and with the researcher and hence provide access to a different layer of meaning.

Given that as workplace researchers we often have to work with fragmented datasets (where issues of access and anonymity are paramount), this project attempts to

\footnotetext{
${ }^{4}$ I need to clarify here that the project did not aim to elicit data in relation to age in the workplace, per se.
} 
provide a detailed case study (Geertz 1973 on thick description) where data was collected continuously over a first period of three months. Overall, the project's long life provided with a rich and systematic dataset which has continuity and also led to a relationship of trust with the participants. The limitations of observing language and analysing discourse are well documents in linguistic research (see Labov 1972 on observer's paradox and Sarangi 2000 on analyst's paradox). However an emic approach and research with the participants can overcome these constraints as much as possible.

I now turn to the data and findings of this study.

\section{5. 'I don't say what I think'. Bringing age to the fore}

Orion staff constitutes a tightly knit team and the core members have worked together for more than 10 years at the time of writing. In this family-size firm the staff interact regularly, are physically in the same office and in line with other literature (e.g., Ram 1999) establish an informal environment. This is particularly relevant as interactants construct themselves according to the norms of both the wider and the local context of the interaction. As Gumperz argued "interpretation of what a speaker wants to convey at any one point rests on socially constructed knowledge of what the encounter is about and what is to be achieved" (Gumperz 1992: 303).

In an informal interview Cynthia mentioned her young age and perceived it as relevant to the challenges she faces at work. Following this I asked Cynthia to elaborate and the excerpts here were provided by Cynthia as examples.

Excerpt $1^{5}$. The team discusses the case of one of the franchise stores which seems to be less willing to comply with the new and enhanced safety regulations Orion (the mother firm) has decided to adopt. The director and owner of the franchise store is represented in observations and interviews as a 'problem' case for Orion and a year later has left the business .

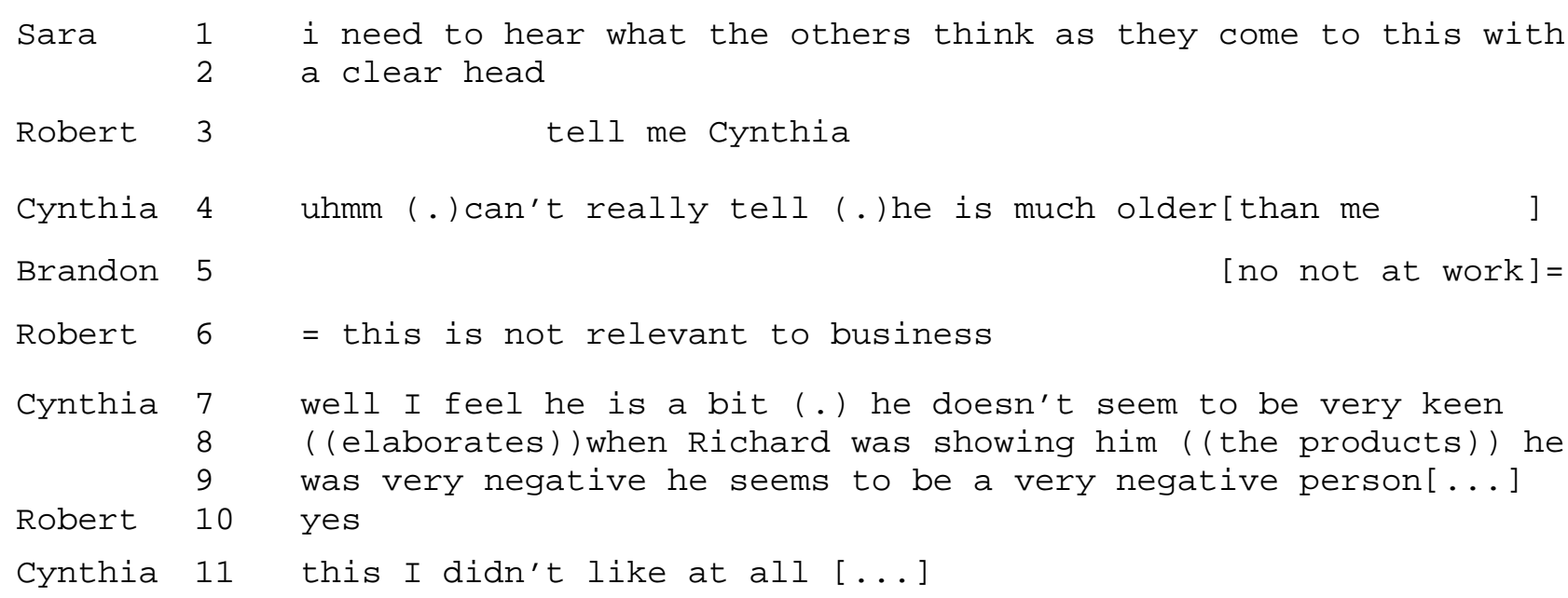
limitations

${ }^{5}$ See appendix for transcription conventions. The excerpt has been edited due to space 


\begin{tabular}{|c|c|c|}
\hline Robert & $\begin{array}{l}12 \\
13\end{array}$ & $\begin{array}{l}\text { on the other hand if he just wants to make money he may become } \\
\text { very good at promoting ((the products)) }\end{array}$ \\
\hline Cynthia & 14 & yes but is he going to play by our standards? $[\ldots]$ \\
\hline Brandon & 15 & his mission is different to ours $[\ldots]$ \\
\hline Cynthia & 16 & yes this I didn't like at all= \\
\hline Brandon & $\begin{array}{l}17 \\
18\end{array}$ & $\begin{array}{l}=\text { thats what he is used to(.) he thought he can do it again but } \\
\text { this is our rules he will have to play by our rules }\end{array}$ \\
\hline Robert & $\begin{array}{l}19 \\
20\end{array}$ & he knew our \\
\hline Sara & $\begin{array}{l}21 \\
22\end{array}$ & $\begin{array}{l}\text { [so the ] bottom line is he doesnt see this as his } \\
\text { main business he sees((the products))only as seasonal products }\end{array}$ \\
\hline ynthia & 23 & 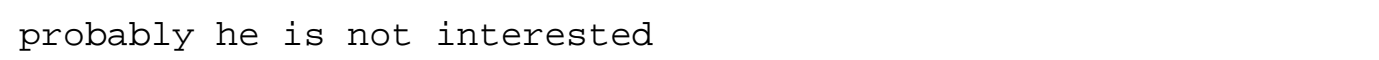 \\
\hline
\end{tabular}

This excerpt draws on an issue well known to Orion that of the practices of their competitors' but also the attitude of the director of one of the stores who is perceived to be non compliant to Orion's policy.

Sara is a core member of the team and opens up the discussion here to include Cynthia who has joined the company a month prior to this meeting. This becomes clearer by Robert's directive in line 3. Cynthia here is asked to comment on her impression of the shop director. Interestingly Cynthia frames her reluctance to provide what turns to be a negative opinion in age terms "he is much older than me". This is immediately resisted by the other members of the team and both Robert and Brandon jump in and reject the categorisation introduced by Cynthia and suggest that it is not relevant to the business in hand. The overlapping talk in line 5 as well as Robert's latching in line 6 are indicative of a strong reaction to Cynthia's utterance. This seems to provide space to Cynthia to develop her negative evaluation. Robert follows up (line 12) and focuses on what he sees as a potentially positive side of the franchisee's attitude. Robert is the director of the company and he plays a central role in decision making activities in Orion (Angouri and Angelidou, fc). This is in line with other research on family business indicating the central role of the owner and director of a family business (Carson and Gilmore 2000). Cynthia voices a direct question in line 14 which has to do with compliance to Orion's standards. Brandon in his role as regional manager seems to believe that the director's attitude will change once it becomes clear that Orion is not prepared to negotiate. Although it is not openly discussed the Orion staff seems to orient towards allowing more time for the franchisee to align themselves with the Orion policy despite their reservations.

Overall the discussion in this excerpt is collaborative and the interactants share the conversational floor without anybody monopolising the discussion. Orion's staff do a lot of work in constructing a team identity and the use of first plural pronouns (e.g., lines $14,15,18$ ) is indicative of that. They also continue each other's utterances, instances of overlapping talk are frequent and collaborative which is in line with the team's interactional style in the corpus. At the same time the team seems to provide a supportive environment for Cynthia to develop her views and contribute on equal 
footing and the team seems to be taking her arguments on board. Cynthia's contribution in the meeting is aligned with the core members of the team. This becomes evident in terms of the amount of talk. Specifically, in the 92 minute meeting Cynthia talking time is very similar to Brandon's, with 18 and 23 minutes respectively. Robert occupied 31 minute of the meeting time and Sara 20 minutes. Cynthia also has accommodated to the team's style in managing their turn taking where both overlapping and being overlapped is unmarked. She enacts her role as communication manager but also performs a team identity in positioning her views in the interaction.

Turning to the interview data, one would reasonably expect that Cynthia would focus on the first part of the meeting but this does not seem to carry a significant weight in the way she constructs her identity in this context. Cynthia argues that what is said in an abstract way does not necessarily reflect how the team or customers would act and states "what else would they say". Instead she focuses on what is represented in lines 17 and 18.

"Cynthia- this is where I really wanted to intervene but I didn't say anything (.) and I wanted to speak so much [...] ((Cynthia refers to Brandon's role as a regional manager)) Brandon always agrees with ((Robert)) always says 'we are the boss, it's our business they will learn the rules' [...] erm hmm well you know how he ((the shop director)) learned? He left the business (.) but I didn't want to offend Brandon.

Jo- Offend?

Cynthia- Yes because I would say 'what you say is not right (.) you have to do something to change their mentality, which you don't do, and best we stop gossiping about what he does and doesn't do and start being proactive in changing behaviours and attitudes"

Cynthia constructs her identity in the interview in relation to what she did not say rather than what was actually said. This is frequent and a recurrent theme emanating from the analysis of the interview data and has to do with the fact that Cynthia often associates the "I don't say what I think" position with her age which is further enhanced by projecting a need to show 'respect' to older colleagues. The concept of respect has been associated with discourses of age (e.g., Coupland 2004; Pecchioni et al. 2004) and becomes a recurrent resource for Cynthia to construct her age identity. Cynthia however does not distinguish between chronological and professional age (her team identity is also of interest here). To take this further, she accounts for framing her initial reluctance in age terms as follows:

"This is my first month (.) I don't know the others that well and more importantly I don't know the job either (.) This was my 
first job and had no experience in my role. They asked me what I thought about him, how could I answer?"

This clearly indicates the complexity of the process and the different facets of her identity that Cynthia brings to the fore simultaneously and which would contradict approaching 'youngness' as a clearly defined chronological stage. The 'first job' refers to Cynthia's lack of previous professional experience and by extension to her chronological age but the emphasis throughout the interview data is on 'on the job' expertise in enacting her professional identity. This Cynthia directly relates to the 'answer back' theme which she associates with her current stage where she feels she has 'grown older'. On a different level, membership to the Orion group and role enactment are brought together in defining the personal and professional self. Both what Cynthia does and her concept of belonging to the group are seen as part of the process of self-identification and related to perceptions of age.

In the following interview excerpt, Cynthia refers to her perception of age identities being projected upon her.

"I feel my age has a different 'weight' for different people at work [...] Sara for example never made me feel awkward because she took time to explain things to me [...] Richard on the other hand always has knee jerk reactions, the minute you say something he needs to come up with a counter argument. Now I can hold my ground and answer back but when I started I was accepting what he was telling me and was a bit embarrassed to confront him, didn't know what exactly was going on. Back when I started I didn't know how to respond and didn't want to be the 'know-itall'"

This excerpt brings together the identities projected upon her along with the self selected identities. The lack of experience 'I didn't know what exactly was going on' is juxtaposed with the willingness to project what she perceives as a collegial persona (and not a 'know it all'). This however becomes more complex when Cynthia refers to her relationship with Brandon and Robert. Brandon is constructed in the interview as projecting a strong identity upon Cynthia and an identity and power struggle becomes evident in the data.

"Brandon is the good example (.) we talk 'work' I say something and he will say 'yes the child is right and we are wrong', when he does this (.) I mean ok (.) (...)" 
The labeling by Brandon creates strong emotional reactions as Cynthia feels her professional identity is fundamentally challenged. This is represented as even more complicated given Cynthia's identity as Robert's daughter ${ }^{6}$.

"This gets on my nerves big time (.) 'the child' and I feel this sets a tone, makes the others see me as a child as well(.) and to make matters more complex my dad is there too hmm I dunno I feel it's like reminding him (.) the child"

This excerpt is particularly significant as Cynthia's reaction to the 'child' label is particularly significant and has to do with a) the projection of an identity on her that, in her view, otherises her from the rest of the team but also b) underlines the fatherdaughter relationship in the firm context. Research on transition in family businesses (Vera and Dean 2005) and particularly on the challenges daughters face (Dumas 1989), has shown that inter-generational transition is often conflictual and more so for daughters (compared to sons). In line with this work, the relationship between Cynthia and Robert is not always perceived as easy in the work context and becomes part of the resources Cynthia draws upon to construct her identity as well as the challenges she feels she faces. In this context Brandon's labeling becomes problematic on more than one level. Cynthia further expands on the issue of being Robert's daughter in the interview.

"My dad sees me as his daughter ((and not a professional))[...] It is very difficult to work with dad on all fronts, I want to address something or to criticize something I need to think how to justify it and put it in nice words so that he doesn't get crossed [...] he goes out with clients and tells them [...] stories from my childhood. How can these people see me as a professional"

In this excerpt Cynthia brings together her front- and back- stage identities. She refers to her difficulty in managing her professional identity within the company in relation to Robert but also how her external identity (in relation to Orion's clients) is threatened by identities projected on her by Robert. By reference to childhood stories and snapshots of what Cynthia perceives as her private life, Robert blurs the boundaries between the personal and the professional which carries increased significance for Cynthia. As references to childhood by adults evoke notions of power imbalance and dependency (see Williams et al. 1997) Cynthia perceives constructing a professional identity in that frame a challenging task (Lambrecht 2005).

This also becomes relevant in the excerpt that follows.

${ }^{6}$ The relationship between Robert and Cynthia in relation to the SME context and intergenerational business transition will be discussed elsewhere 
Excerpt 2. The team discusses the issue of the new safety regulations and the reactions of Orion's associates who are represented as resisting introducing the new policy within Orion's time frame. Cynthia works on this project and the team discusses her experience and impressions.

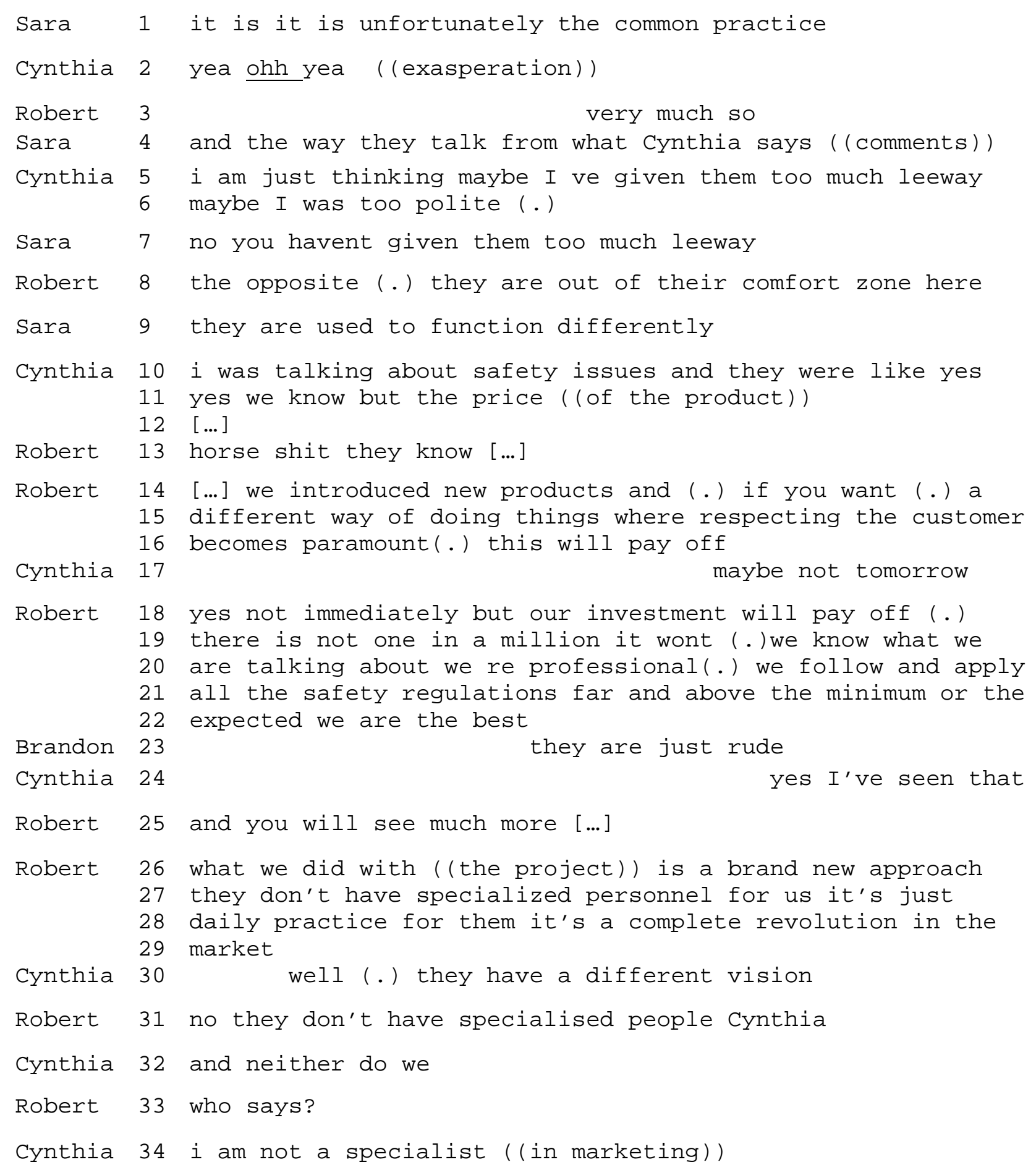




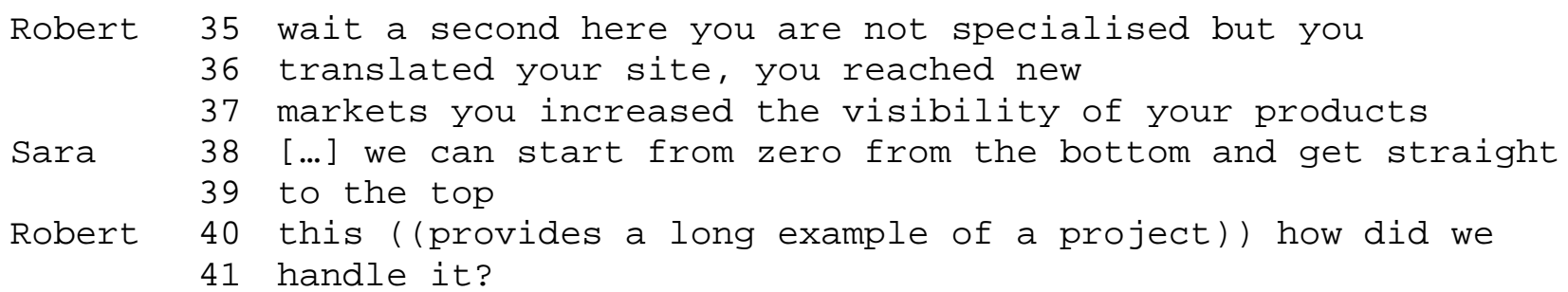

Orion has invested in introducing a new way of promoting the company's main products -which are subject to strict safety regulations, restrictions on the use and sale of the products to underage customers - The firm has also introduced a new company policy and is requiring all the franchisees to adhere to the new rules. The issue of compliance to the safety regulations has preoccupied Orion's staff over a series of meetings and a long period of time.

Orion's team often comes together in informal meetings which occur daily and they provide the main context for both small talk and also problem solving and decision making. The boundaries between social and work talk are anything but clear cut (Holmes and Stubbe 2003) but this is even more apparent in the Orion informal context (see also Cynthia's reference to gossiping in interview excerpt 1).

The team again constructs a strong collective identity which becomes evident from the first three lines where Sara, Cynthia and Robert co-construct the common practices 'in the market' as different to their own. The style is informal (e.g., line 2 'yea ohh yea') and Cynthia raises a concern about her own practices in lines 5 and 6 in response to Sara's comment on the language used (implying perceived impoliteness see also line 23). Sara and Richard again reject Cynthia's concerns and relate the associates' reaction to the new policy Orion is trying to implement.

Cynthia in the interview elaborates on the feeling that the franchisee directors did not take her seriously 'in the beginning' although she was in charge of briefing them. Cynthia seems to have thought that their behaviour was triggered by her age and gender identity and also her being polite.

"they were trying to fool me (.) but I didn't know why back then and I was thinking maybe because I am a young woman maybe because I am too polite I didn't know I couldn't understand why"

As in the meeting excerpt Cynthia brings chronological age to the fore but this time associated with her gender identity and interactional style. By the process of self categorisation, the identity of a young polite woman implicates normative representations of female employees facing challenges in the job market (Baxter 2010) in Cynthia's discourse. This however here serves as a resource to self reject the relevance of these facets of her identity and Cynthia goes on to deem them not salient in line with the meeting participants' reaction (lines 7,8,9) where the team suggests the franchisees reactions are associated with Orion's policy. The constant reference to the 'beginnings' (e.g., 'in the beginning I was trying to brief them', 'back 
then', 'in the beginning they were trying to fool me') evokes Cynthia's professional age and on the job experience which is directly associated with her professional identity and self positioning.

The team's reaction escalates with Robert's strong language in line 13. This is unmarked in the Orion context and often the team uses expletives and strong language, particularly Robert and Sara (see Angouri and Angelidou, fc). Strong language becomes a resource for constructing an informal context but also emphasises the power balance in the team (Daly et al. 2004) with Robert having a 'central' role and Sara consistently constructing herself as 'second in command'. The team continues in building on each other's utterances and Robert expands on praising the company which reaches a pick in lines 28 and 29 where Roberts refers to a 'revolution in the market'. Cynthia in a move that seems to contradict her alignment with the team so far prefaces her utterance with a pragmatic marker (well) and refers to a 'different vision'. Discourse markers are multifunctional but well can soften the initiation of disagreement (Cuenca 2008) and the pause immediately after the particle further enhances this effect. This is immediately contested by Robert by a direct disagreement (No). Cynthia however (in line 32) challenges him directly ('neither do we') and the disagreement escalates in lines 33 and 34 where Cynthia, who has also been working on the company's marketing, rejects a specialist identity projected on her. Robert and Sara work together to contest Cynthia's claim. Sara aligns with Robert and makes a broader evaluative comment about the company's achievements which is further supported by Robert's drawing on a past success project.

Cynthia's moves in this excerpt are of interest as she starts by aligning herself to the team's position but then moves on to challenge Robert directly and also challenges the 'speacialised' identity that has been projected upon herself and Orion's staff. The team constructs Cynthia as a specialised professional where Cynthia resists this identity and focuses on her lack of expertise in marketing.

In the interview Cynthia also constructs a professional identity and elaborates on her intentions. "What I wanted to communicate is not that our firm is not good but we shouldnt underestimate our competitors (...) translating a site has nothing to do with marketing the way I see it"

Despite her direct reaction in line 34 Cynthia let it drop and from line 35 on Robert and Sara develop on the topic. This silence is again foregrounded in the interview data where Cynthia argues "you see I don't say anything again because this would start an argument ((with Robert))". The personal relationship and dynamics between Cynthia and Robert is indirectly invoked here. Having to manage being the director's daughter and a professional, presents challenges that have been addressed in relevant literature and become very prominent in this case study too (Salganicoff 1990). Cynthia has to manage her own identity and the identities projected upon her by the rest of the team. The web of power relationships and the conflicting identities Cynthia feels she needs to joggle are nicely captured in her saying 
"I sometimes think they ((Orion team) will let go because of who I am so that I won't get annoyed ((because of me being my father's daughter))"

(9)

\section{Discussion and concluding remarks}

The analysis of the data has shown the dynamic process of identity construction. Cynthia draws on a range of resources to construct the identities she claims for herself and to negotiate the identities that are projected upon her by Robert as her father and the team. Even though 'age' identities are important resources for self and other positioning (Coupland 2009), a closer look indicates that separating chronological age from other facets of Cynthia's identity, and particularly professional identity, would reduce and oversimplify the process.

Through her interactions and the interview data, Cynthia follows a complex architecture in constructing her professional identity which can be illustrated as in Figure 1 . This representation is evidently reducing the complex nature of identity work and is not meant to provide an identity typology but a summary of the data discussed here.

Wider SME Socio-economic context

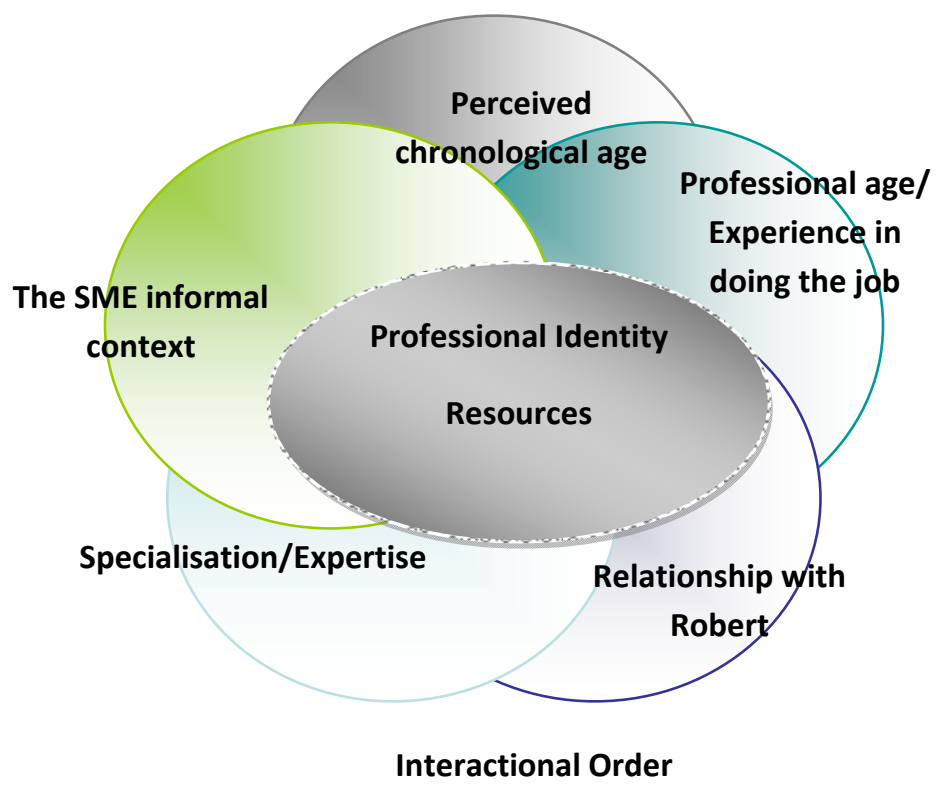

Figure 1. The resources Cynthia draws upon in constructing her professional identity 
Drawing a parallel with research on gender, recent work (e.g., Harrington et al. 2008) makes a case for a social constructionist, performativity theory informed view of identity which moves away from polarisation. This applies directly to research on age and highlights the need to move away from focusing on age groups in a static way. Coupland et al. (1991 and later work) have shown how the focus on particular sociodemographic categories (the elderly in the case of this research) cannot be void of a study on the processes of categorisation and the discursive construction of these categories in talk. In other words 'elderliness' (in the case of Coupland et al.) or 'youngness' is not something people have or are but something they actively do is and projected upon them in the process of identity negotiation and the roles they are (expected or not) to assume within their group.

Recent research (e.g., Aapola 2002) has also approached age as historically, socially and culturally constructed and highlights the view that chronological age is just one aspect of a complex phenomenon. Aapola's research on students' autobiographical notes shows the relationship between age and perceptions of power and status in society. Hence while the students tended to report feeling 'older', aspiring to the status of adults in society, adults often report feeling 'younger' than their chronological age (Bultena and Powers 1978), indicating the value placed in 'youth' as an ideal. Constructing 'youngness' efficiently seems to be particularly desirable when it goes with the power and status of roles typically occupied by (chronologically older) adults. As suggested by Aapola "[t]he discourses of age may have material and social consequences, depending on the types of cultural and institutional discursive practices that are connected to them” (2002: 312).

Cynthia in the interview context orients towards a range of strategies she has developed for constructing herself in the Orion context. Her self-categorisation of (professionally) young along with her personal identity as the director's daughter seem to impose a need on her to act 'more professionally than professional' which in her data is indexed by : a) Providing tangible evidence for her reasoning "all the time" b) Trying to set limits and roles and sort out whose responsibility is what c) Adapting (and thinking) of the best way to say things so that offence will be avoided d) Doing someone else's work herself but sanction inefficiency by bringing it up in meetings where the team is present e) Questioning others "The older I get the less I trust people"

The analysis of the two meeting excerpts and the interview data has shown how Cynthia enacts the first three although the consideration of not causing offence seems, at times, to result in silence. This however is not particular to Cynthia's case as often employees would recycle a point in a later meeting or manoeuvre to achieve their goals (Holmes and Marra 2004). For Cynthia however this seems to have repercussions in her self -and other- positioning in this SME context.

"I always need to consider if I have to pick on things or I should let go so that I won't be annoying and frustrating"

In closing this paper, the discussion has attempted to show the complexities of enacting 'youngness' in the context of one SME company. Research in organisation 
studies (see relevant work in Jablin and Putnam 2000) and sociolinguistic research (e.g., Holmes 2006; Holmes, Marra and Vine 2011) have shown that aspects of employees' identities such gender, ethnicity, sexual orientation can and often do become sites of oppression and power imbalance. Age is still under researched from this point of view. Despite clear evidence that groups of employees are marginalized and negative stereotypes are projected upon/create expectations of performance for young or old or something in between employees, this area has not as yet attracted significant attention and further research is needed to shed light on the complex phenomenon particularly in the under researched small firm/family business context.

\section{Appendix}

\section{Transcription Conventions:}

All names used in extracts are pseudonyms. Line divisions are intended to support understanding and typically represent sense unit boundaries. There has been minor editing for reasons of space and ease of reading.

\begin{tabular}{|l|l|}
\hline I & $\begin{array}{l}\text { Left square brackets indicate a point of overlap onset. } \\
\text { Right square brackets indicate a point at which two } \\
\text { overlapping utterances both end, where one ends while the } \\
\text { other continues, or simultaneous moments in overlaps } \\
\text { which continue. } \\
\text { Equal signs indicate continuous utterance with no break or } \\
\text { pause and/or latch. }\end{array}$ \\
(.) & $\begin{array}{l}\text { A dot in parentheses indicates an unmarked/short pause. } \\
\text { Double parentheses are used to indicate transcriber's } \\
\text { comments. } \\
\text { ((NOTES )) }\end{array}$ \\
Emphasis & $\begin{array}{l}\text { emphasis. } \\
\text { Text omitted }\end{array}$ \\
\hline [...] &
\end{tabular}




\section{References}

Aapola, Sinikka (2002) Exploring dimensions of age in young people's lives. A discourse analytical approach. Time and Society 11.2/3: 295-314.

Angouri, Jo, and Evi Angelidou (forthcoming) Managing the director's views; Decision making in a small firm context. In S. Mada, R. Saftoiu, and M.Gheorghe (eds.), Professional communication across languages and cultures. Amsterdam: Benjamins Publishing Company, Dialogue Studies series.

Angouri, Jo, and Meredith Marra (eds.) (2011) Constructing Identities at Work. London: Palgrave.

Angouri, Jo (2010) Quantitative, qualitative or both? Combining methods in linguistic research. In Lia Litosseliti (ed.), Research Methods in Linguistics. London: Continuum, pp. 29-49.

Bamberg, Michael, Anna De Fina, and Deborah Schiffrin (2011) Discourse and identity construction. In Seth J. Schwartz, Luyckx Koen, and Vivian L. Vignoles (eds.), Handbook of identity theory and research. Berlin/New York: Springer Verlag, pp. 177-199.

Baxter, Judith (2010) The Language of Female Leadership. Basingstoke: Palgrave Macmillan.

BIS (2010) Small and Medium-sized Enterprise (SME) Statistics for the UK and Regions 2009. Statistical Press Release. Available from http://stats.bis.gov.uk/ed/sme/Stats_Press_release_2009.pdf Accessed January 2011.

Block, David (2000) Problematizing interview data: Voices in the mind's machine?. TESOL Quarterly 34.4: 757-763.

Bultena, Gordon L., and Edward Powers (1978) Denial of aging: Age identification and reference group orientation. Journal of Gerontology 33: 748-755.

Burke, Peter, and Judy C. Tully (1977) The measurement of role identity. Social Forces 55: 881-97.

Cameron, Deborah, Elizabeth Frazer, Penelope Harvey, Ben Rampton, and Kay Richardson (1992) Researching Language. Issues of Power and Method. London: Routledge.

Cameron, Deborah (2009) Theoretical issues for the study of gender and spoken interaction. In Pia Pichler, and Eva M. Eppler (eds.), Gender and spoken interaction. London: Palgrave Macmillan, pp. 117.

Carson, David (1990) Some exploratory models for assessing small firms' marketing performance, a qualitative approach. European Journal of Marketing 24.11: 1-51.

Cassell, Catherine, Sara Nadin, Melany Gray, and Chris Clegg (2002) Exploring human resource management practices in small and medium enterprises. Personnel Review 31.6: 671-692.

Chambers, Jack (1995) Sociolinguistic theory: Linguistic variation and its social significance. Oxford: Blackwell.

Cooley, Charles (1902) Human nature and the social order. New York: Charles Scribner's Sons.

Coupland, Nikolas (2004 $2^{\text {nd }}$ ed.) Age in social and sociolinguistic theory. In Jon F. Nussbaum, and Justine Coupland (eds.), Handbook of Communication and Aging Research. Hillsdale, NJ: Erlbaum, pp. 69-90. 
Coupland Justine, Nikolas Coupland, Howard Giles, and Karen Henwood (1991a) Formulating age: Dimensions of age identity in elderly talk. Discourse Processes 14: 87-106.

Coupland, Justine, Nikolas Coupland, and Karen Grainger (1991b) Intergenerational discourse: Contextual versions of aging and elderliness. Aging and Society 11:189-208.

Coupland, Justine (2009) Time, the body and the reversibility of ageing: Commodifying the decade. Ageing \& Society 29.6: 951-75.

Cuenca, Maria-Josep (2008) Pragmatic markers in contrast: The case of 'well'. Journal of Pragmatics 40.8: 1373-1391.

Davies, Bronwyn, and Rom Harré (1990) Positioning: The discursive production of selves. Journal for the Theory of Social Behavior 20.1: 43-63.

Dumas, Colette (1989) Understanding the father-daughter and the father-son dyads in family-owned businesses. Family Business Review 2: 31-47.

Duncan, Colin, and Wendy Loretto (2004) Never the right age? Gender and age-based discrimination in employment. Gender, Work and Organization 11.1: 95-115.

Eckert, Penelope (1997) Age as a sociolinguistic variable. In Florian Coulmas (ed.), The Handbook of Sociolinguistics. Oxford: Blackwell, pp. 151-167.

Engeström, Yrjö (1987) Learning by expanding: An activity-theoretical approach to developmental research. Helsinki: Orienta-Konsultit.

Gecas, Viktor (1982) The self-concept. Annual Review of Sociology 8: 1-33.

Gee, James P. (1999) An introduction to critical discourse analysis. London: Routledge.

Geertz, Clifford (1973) Thick description: Toward an interpretive theory of culture. In The Interpretation of Cultures: Selected Essays. New York: Basic Books, pp. 3-30.

Giles, Howard, Nikolas Coupland, and Justine Coupland (1991) Accommodation theory: Communication, context, and consequence. In Howard Giles, Justine Coupland, and Nikolas Coupland (eds.), Contexts of Accommodation: Developments in Applied Sociolinguistics. Cambridge: Cambridge University Press, pp. 1-68.

Granovetter, Mark (2000) The economic sociology of firms and entrepreneurs. Enterneuship: The Social Science View 1: 244-275.

Gumperz, John (1982) Discourse strategies. Cambridge: Cambridge University Press.

Gumperz, John (1992) Interviewing in intercultural situations. In Paul Drew, and John Heritage (eds.), Talk at Work. Cambridge: Cambridge University Press, pp. 302-327.

Harrington, Kate, Lia Litosseliti, Helen Sauntson, and Jane Sunderland (eds.) (2008) Gender and Language Research Methodologies.Basingstoke: Palgrave Macmillan.

Harwood, Jake, Howard Giles, and Ellen B. Ryan (1995) Aging, communication, and intergroup theory: Social identity and intergenerational communication. In Jon F. Nussbaum, and Justine Coupland (eds.), Handbook of communication and aging research. Hillsdale, NJ: Lawrence Erlbaum Associates, pp.133159. 
Hitlin, Steven (2003) Values as the core of personal identity: Drawing links between two theories of self. Social Psychology Quarterly 66: 118-137.

Hogg, Michael, A., Elizabeth A. Hardie, and Katherine J. Reynolds (1995) Prototypical similarity, selfcategorization, and depersonalized attraction: A perspective on group cohesiveness. European Journal of Social Psychology 25: 159-177.

Holliday, Ruth (1995) Investigating Small Firms: Nice Work?. London: Routlege.

Holmes, Janet, and Meredith Marra (2004) Leadership and managing conflict in meetings. Pragmatics 14.4: 439- 462.

Holmes, Janet, and Maria Stubbe (2003) Power and Politeness in the Workplace: A. Sociolinguistic Analysis of Talk at Work. Harlow: Pearson.

Holmes, Janet (2006) Gendered Talk at Work. Oxford: Blackwell.

Holmes, Janet, Meredith Marra, and Bernadette Vine (2011) Leadership, Discourse, and Ethnicity. Oxford: Oxford University Press.

Jablin, M. Frederic, and Linda L. Putnam (eds.) (2001) The new handbook of organizational communication: Advances in theory, research and methods. Thousand Oaks: Sage.

Jones, Oswald (2003) Competitive advantage in SMEs: Toward a conceptual framework. In Oswald Jones, and Fiona Tilley (eds.), Competitive Advantage in SMEs: Organising for Innovation and Change. Chichester: Wiley, pp.135-156.

Labov, William (1972) Sociolinguistic Patterns. Philadelphia: University of Pennsylvania Press.

Labov, William (1994) Principles of linguistic change. 1: Internal factors. Oxford: Blackwell.

Lambrecht, Johan (2005) Multigenerational transition in family businesses: A new explanatory model. Family Business Review. 18: 267-289.

Le Page, Robert B., and Andrée Tabouret-Keller (1985) Acts of identity. Cambridge: Cambridge University Press.

Locher, Mirriam A. (2004) Power and Politeness in Action: Disagreement in Oral Communication. Berlin: Mouton de Gruyter.

Mead, George (1934) Mind, Self and Society. Chicago: University of Chicago Press.

Mørck, Line L. (2011) Studying empowerment in a socially and ethnically diverse social work community in Copenhagen, Denmark. ETHOS, Journal of the Society for Psychological Anthropology. 39.1: 115-137.

Neathey, Fiona (2006) The impact of age discrimination legislation on small and medium-sized enterprises. Acas Research and Evaluation Section. Available from http://www.acas.org.uk/media/pdf/k/i/research-paper-04-06-accessible-version-July-2011.pdf

Odell, Lee, Dixie Goswami, and Anne Herrington (1983) The discourse-based interview: A procedure for exploring the tacit knowledge of writers in nonacademic settings. In P. Mosenthal, L. Tamor, and S.A. Walmsley (eds.), Research on writing: Principles and methods. New York: Longman, pp. 221-236. 
Patrickson, Margaret, and Rob Ranzijn (2004) Bounded choices in work and retirement in Australia. Employee Relations 26: 422-432.

Pecchioni Loretta, Hiroshi Ota, and Lisa Sparks (2004) Cultural issues in communication and aging. In Jon F. Nussbaum, and Justine Coupland (eds.), Handbook of communication and aging research. Mahwah: Erlbaum, pp. 167-207.

Performance and Innovation Unit (2000) Winning the Generation Game. London: The Stationary Office.

Ram, Monder (1999) Managing autonomy: Employment relations in small professional service firms. International Small Business Journal 17.2: 13-30.

Roberts, Ian (2006) Taking age out of the workplace: Putting older workers back. Work, Employment and Society 20.1: 67-86.

Roberts, Celia, and Srikant Sarangi (2003) Uptake of discourse research in interprofessional settings: Reporting from medical consultancy. Applied Linguistics 24.3: 338-359.

Salganicoff, Matilde (1990) Women in family businesses: Challenges and opportunities. Family Business Review 3.2: 125-137.

Sarangi, Srikant (2000) Activity types, discourse types and interactional hybridity: The case of genetic counselling. In Srikant Sarangi, and Malcolm Coulthard (eds.), Discourse and Social Life. London: Pearson, pp. 1-27.

Sarangi, Srikant (2010) Reconfiguring self/identity/status/role: The case of professional role Performance in healthcare encounters. In James Archibald, and Garzone Garzone (eds.), Actors, Identities and Roles in Professional and Academic Settings: Discursive Perspectives. Berne: Peter Lang, pp. 2754.

Schwartz, Seth J., Koen Luyckx, and Vivian L. Vignoles (eds.) (2011) Handbook of identity theory and research. New York: Springer.

Snape, Ed, and Tom Redman (2003) Too old or too young? The impact of perceived age discrimination. Human Resource Management Journal 13.1:78-89.

Spence, Laura J. (1999) Does size matter? The state of the art in small business ethics. Business Ethics: A European Review 8.3: 163-174.

Spence, Laura J.(2004) Small firm accountability and integrity. In George G. Brenckert, Corporate Integrity and Accountability. Thousand Oaks, California: Sage, pp.115-129.

Stets, Jan E., and Peter J. Burke (2000) Identity theory and social identity theory. Social Psychology Quarterly 63: 224-237.

Stryker, Sheldon (1980) Symbolic Interactionism: A Social Structural Version. Menlo Park: Benjamin Cummings.

Tajfel, Henri, and John C. Turner (1979) An integrative theory of inter-group conflict. In William G. Austin, and Stephen Worchel (eds.), The social psychology of intergroup relations. Monterey, CA: Brooks-Cole, pp. 7-25.

Terry, Deborah .J., Michael A. Hogg, and Katherine M. White (1999) The theory of planned behaviour: Self-identity, social dentity and group norms. British Journal of Social Psychology 38.3: 225-44. 
Thoits, Peggy A. (1986) Multiple identities: Examining gender and marital status differences in distress. American Sociological Review 51.2: 259-272.

Trudgill, Peter (1988) Norwich revisited: Recent linguistic changes in an English urban dialect. English World-Wide 9.1: 33-49.

Trudgill, Peter (1974) The social differentiation of English in Norwich. Cambridge: Cambridge University Press.

Vera, Carolina F., and Michelle A. Dean (2005) An examination of the challenges daughters face in family business succession. Family Business Review 18.4: 321-345.

Woodhams, Carole, and Ben Lupton (2006) Gender-based equal opportunities policy and practice in small firms: The impact of HR professionals. Human Resource Management Journal 16.1: 74-97.

Williams, Angie, Justine Coupland, Annette Folwell, and Lisa Sparks (1997) Talking about generation X defining them as they define themselves. Journal of Language and social Psychology 16: 251-276.

JO ANGOURI is a Senior Lecturer at the University of the West of England, Bristol, UK. Her research focus is language in the workplace. Jo has published work on meeting talk, leadership, gender, workplace written discourse and (foreign) language use and language policy in the workplace. She has published in a range of specialist and wide readership journals and has recently co-edited (with Dr Meredith Marra) a volume entitled Constructing Identities at Work. Her current work includes a comparative analysis of discourse in business meetings and a multidisciplinary project on hospital talk.

Address: UWE, Bristol, 3E10c, Frenchay Campus, Coldharbour Lane, BS16 1QY, Bristol, UK. E-mail: Jo.Angouri@uwe.ac.uk 